Australasian Journal of Logic

\title{
Resolving Quine's Conflict: A Neo-Quinean View of the Rational Revisability of Logic ${ }^{1}$
}

\author{
Amanda Bryant, CUNY Graduate Center \\ abryant@gradcenter.cuny.edu
}

A number of authors have noted that Quine seems to be of two minds regarding the rational revisability of logic (Arnold and Shapiro 2007, Haack 1974a, Dummett 1978a, Priest 2006a). Although Quine is clearly committed to the rational revisability of logic, some of his other philosophical commitments appear to rule out its possibility. His commitment to rational revisability is clear because he explicitly declares it and because at least two of his claims imply it, namely: i) the web of belief is universally revisable and ii) there are criteria for choice among logics. However, Quine's principle of charitable translation and his change of logic, change of subject argument appear to conflict with the rational revisability of logic. I argue that upon analysis, the apparent tension dissolves, and Quine consistently holds a revisability thesis. However, Quine's revisability thesis is weak, because it severely restricts the manner in which revision can occur. I argue that a stronger revisability thesis is consistent with the spirit of Quine's work. Since I do not claim that the stronger thesis is present in Quine's work, explicitly or implicitly, I call the stronger thesis Neo-Quinean. To articulate the Neo-Quinean thesis, I distinguish between: 1) logic in theory and logic in practice, 2) laymen's logic and considered logic, and lastly 3 ) evolutionary revision and revolutionary revision. The Neo-Quinean thesis is that all logics are revisable in some manner or other: laymen's practice is subject only to evolutionary revision, while considered theories and practices are subject to both evolutionary and revolutionary revision. My purpose here is to show that the Neo-Quinean view is a coherent theoretical option.

\footnotetext{
${ }^{1}$ I wish to thank Graham Priest for his invaluable feedback at various stages in the development of this paper. Thanks also to Hartry Field for comments and encouragement on an early draft. Thanks to Zach Weber and an anonymous reviewer for their suggestions. Finally, thank you to the audience members at my talk "Resolving the Quinean Conflict: Groundwork for a Neo-Quinean View of the Rational Revisability of Logic" on January 26, 2016 at Frontiers of Non-Classicality: Logic, Mathematics, Philosophy for their helpful questions and comments. This research was supported by the Social Sciences and Humanities Research Council of Canada.
} 


\section{$\S 1$ For Rational Revisability}

As I will use the term, to revise logic is to start or stop accepting a logical principle or set of principles, or to start or stop using the principle or principles. $^{2,3}$ For logic to be rationally revisable is for it to be possible to revise logic a) for reasons, and b) without violating any of the necessary conditions of rationality. ${ }^{4,5}$ So a rational revision includes not only a change in principles, but some justificatory work as well. I remain neutral on the precise conditions of rationality.

There are a number of reasons to think that Quine is firmly committed to the rational revisability of logic, so understood. First, he explicitly avows the rational revisability of logic. In Philosophy of Logic, he writes, "Logic is in principle no less open to revision than quantum mechanics or the theory of relativity" $(1970,100)$. Since physics is demonstrably revisable, and rationally so, then logic must be rationally revisable. Moreover, this avowal seems not to be made uncritically. Rather, other elements of Quine's philosophy support the rational revisability of logic.

\section{$\S 1.1$ Universal Revisability}

First, Quine's commitment to the universal revisability of the web of belief implies the rational revisability of logic. In Two Dogmas of Empiricism, he describes the web of belief as follows:

The totality of our so-called knowledge or beliefs ... is a man-made fabric which impinges on experience only along the edges.... A conflict with experience at the periphery occasions readjustments in the interior.... Reevaluation of some statements entails reevaluation of others, because of their logical interconnections - the logical laws being in turn simply certain further statements of the system. (1951, 42)

Our beliefs form a network that we rationally strive to keep in full alignment. The edges of the web are highly dependent on experience. If experience comes into conflict with certain beliefs, we revise them to make them better cohere with experience. ${ }^{6}$ Beliefs that are minimally affected by experience inhabit the centre of the web: "highly theoretical statements of physics or logic or ontology ... may be thought of as relatively centrally located within the total network"

\footnotetext{
${ }^{2}$ For my purposes here, I bracket cases where one neither accepts nor rejects the principle in question (see Warren 2016) and where elements of the belief base are fuzzy (see Booth and Richter 2005).

${ }^{3}$ See for example Ripley (2013b), Roeper (2004), and Beall (2009).

${ }^{4}$ For examples of the sorts of reasons for which one might revise, see Burgess (2012), Dummett (1978b), Field (2003), Haack (1974b) and (1996), Mares (2002), Priest (2006b) and (2008), Putnam (1957) and (1983), Salerno (2000), and Wright (1992).

${ }^{5}$ For arguments that logic is not rationally revisable, see Berger (2011), Katz (2000, §3.3), and Shapiro (2000).

${ }^{6}$ See Chase (2012) for two formalizations of Quinean revisability.
}

Australasian Journal of Logic (14:1) 2017, Article no. 2 
(1951, 44). Revisions to those central beliefs create a "devastatingly widespread unfixing of truth values" $(1960 \mathrm{~b}, 60)$. The central beliefs are so entrenched and integral to the shape of the web that altering them necessitates widespread revision.

The centrality of logic to the web prima facie undermines its rational revisability, because one might think that logic is so distant from the periphery that there could never be a rational impetus to revise it. However, Quine does not take the central place of logic within the web of belief to undermine its rational revisability. Rather, he famously defends universal revisability: "no statement is immune to revision" $(1951,43)$. He goes on to say:

Revision even of the logical law of the excluded middle has been proposed as a means of simplifying quantum mechanics; and what difference is there in principle between such a shift and the shift whereby Kepler superseded Ptolemy, or Einstein Newton, or Darwin Aristotle. $(1951,43)$

If these highly theoretical, central beliefs are subject to revision, then so too is logic. Revisions to logical beliefs are a species of theoretical revolution and, if his examples are any guide, rational revolution. According to Quine, the web of belief is universally rationally revisable, so logic is rationally revisable.

\section{$\S 1.2$ Criteria for Choice Among Logics}

Quine also implies rational revisability when he gives criteria for choice among logics. First, he claims that any revision should be guided by the "maxim of minimum mutilation" $(1970,85)$. This is a conservative principle of theory choice, but a principle of choice nonetheless. He also says that any revision should minimize the loss of clarity, elegance, efficiency, simplicity, beauty, familiarity, and convenience (1970, 85-6). One should, for example, avoid the introduction of paradox $(1970,85)$. Moreover, not all of the criteria are equally important; sometimes we must weigh them against one another. For instance, Quine points out, the mathematician "admits the irrational numbers so as to round out arithmetic and simplify computation" (1970, 86). Ceteris peribus, "the less such fat the better," but since the additional theoretical machinery simplifies computation, "it is rather to be excused than excised" $(1970,86)$. In this case, convenience trumps elegance. This shows that it can be rational to revise even when a theoretical alternative does relatively poorly on some criterion. So Quine specifies a number of criteria for rational theory choice and gestures toward a method of choice that weighs those criteria against one another.

Admittedly, Quine's reason for articulating the criteria is to show that rationally, one ought not to revise classical logic. He thinks that so-called deviant logics do poorly on the criteria he names:

let us not underestimate the price of a deviant logic. There is a serious loss of simplicity, especially when the new logic is not even

a many-valued truth-functional logic. And there is a loss, still more serious, on the score of familiarity. $(1970,86)$ 
Furthermore, using deviant logic is somehow a "handicap" $(1970,86)$. Intuitionistic logic, in particular, "lacks the familiarity, the convenience, the simplicity, and the beauty of our logic" $(1970,86)$. Unfortunately, Quine does not spell out these criteria, how to weigh them, why we should use them, or how exactly deviant logics violate them. So his discussion of criteria for theory selection, and of the failure of deviant logics to satisfy them, is incomplete. Nevertheless, the fact remains that he specifies criteria. So his view seems to be that given the current, contingent state of theoretical development, we ought not to revise classical logic, but that logic is in principle rationally revisable. If logic were not in principle rationally revisable, there would be no question of choosing among logics and no use for criteria of theory choice. In sum, Quine is clearly committed to the rational revisability of logic, because 1) he explicitly avows it, 2) he asserts the universal revisability of the web of belief, and 3) he articulates criteria for choice among logics, as well as a choice procedure that involves weighing criteria against one another.

\section{§2 Against Rational Revisability}

\section{§2.1 Charitable Translation}

Although Quine's commitment to rational revisability is clear, some of his other philosophical commitments appear to conflict with it. In Chapter 2 of Word and Object, Quine argues for a principle of charity with respect to the translation of non-English sentences and the interpretation of English sentences. According to Quine, "Wanton translation can make natives sound as queer as one pleases. Better translation imposes our logic upon them" (1960b, 58). For instance, he says, suppose that the members of some tribe "accept as true a certain heathen sentence of the form ' $\mathrm{q}$ ka bu q' " and we translate it 'p and not p' (1960a, 352). In Quine's view, the translation is bad, because "If any evidence can count against a lexicographer's adoption of 'and' and 'not' as translations of 'ka' and 'bu', certainly the natives' acceptance of 'q ka bu q' as true counts overwhelmingly" (1960a, 352). It counts overwhelmingly because:

assertions startlingly false on the face of them are likely to turn on hidden differences of language.... The common sense behind the maxim is that one's interlocutor's silliness, beyond a certain point, is less likely than bad translation - or, in the domestic case, linguistic divergence. (1960b, 59)

On Quine's view, it is not inconceivable that the native really does accept a contradiction as true, but it is far more likely that we have mistranslated her utterances. The best translation assumes the more likely scenario. So "[w]e build the logic into our manual of translation" $(1970,82)$. Regarding the interpretation of English sentences, Quine says:

when to our querying of an English sentence an English speaker answers 'Yes and no', we assume that the queried sentence is meant 
differently in the affirmation and negation; this rather than that he would be so silly as to affirm and deny the same thing. (1960b, 59)

When a speaker appears to assert a contradiction, the charitable listener interprets away the contradiction. According to Quine's principle of charity, the best interpretation of an utterance imposes classical logic on it. ${ }^{7}$

An alternate formulation of the principle of charity is the motto "Save the obvious" (1970, 82). Quine explains:

I am using the word 'obvious' in an ordinary behavioral sense, with no epistemological overtones. When I call ' $1+1=2$ ' obvious to a community I mean only that everyone, nearly enough, will unhesitatingly assent to it, for whatever reason; and when I call 'It is raining' obvious in particular circumstances I mean that everyone will assent to it in those circumstances. $(1970,82)$

That which is obvious invokes assent from nearly everyone in a given community, under the right sorts of circumstances. According to Quine, "every logical truth is obvious, actually or potentially," where it is clear from the context that the logical truths in question are those of classical logic $(1970,82){ }^{8}$ That is, every classical logical truth "is either obvious as it stands or can be reached from obvious truths by a sequence of individually obvious steps" $(1970,83)$. In Quine's view, since the principles of classical logic are obvious and since translation and interpretation should save the obvious, translation and interpretation should impose classical logic. Any deviance will be translated away in the interests of preserving the obvious.

Non-classical logicians should not find the principle of charity, or of obviousness preservation, particularly charitable. When applied to logic, the principle requires that when someone attempts to articulate a heterodox logic, we "impute our orthodox logic to him, or impose it upon him, by translating his deviant dialect" $(1970,81)$. According to Quine:

even the most audacious system-builder is bound by the law of contradiction... [because if] he were to accept contradiction... we would proceed to reconstrue his heroically novel logic as a noncontradictory logic, perhaps even as familiar logic in perverse notation. (1960b, 59)

\footnotetext{
${ }^{7}$ Though Quine privileges classical logic in his formulation of the translation argument, note that the argument can be framed in neutral terms. On that neutral characterization, charitable interpretation in accordance with one's own antecedently accepted logic, whatever that may be, precludes communication of alternative logics. In other words, the problem of charitable translation is symmetric. I am grateful to an anonymous reviewer for pointing this out.

${ }^{8}$ Of course, not everyone agrees that the principles of classical logic are in fact obvious. Priest, for instance, comments "the claim that logic is obvious is mind-numbingly false" (2006a, 172). See also Cobreros et. al. (2012) and Ripley (2013a), who claim that classical principles like explosion are counterintuitive.
}

Australasian Journal of Logic (14:1) 2017, Article no. 2 
In the interests of good translation, the listener will not countenance deviance, but will instead translate it away. This claim leads some interpreters of Quine, such as Haack, to attribute to him the view that "apparent conflict in logic should always be accounted the result of mistranslation" (Haack 1996, 14, original emphasis). According to Haack, if that is the case, then "there can be no genuine rivals to classical logic" $(1996,15)$. To the extent that revision requires alternative logics, if there are no rivals, there can be no revision. On Haack's reading, Quine's principle of charitable translation precludes rival logics, therefore it precludes revising logic. If so, then Quine is inconsistent regarding the rational revisability of logic.

But this is too quick. The principle of translation and interpretation allows that rivalry may be countenanced by a single individual, and the impetus to revise may be arrived at independently of others. That is because, at the individual level, there is no question of translation or interpretation, since individual reflection is not communicative and since the translation argument kicks in only when communication enters the picture. So the translation argument does not rule out individual revisions undertaken independently of others.

However, one might object that to countenance rival systems, an individual must imagine a counterpart who uses a rival system and interpret her counterpart's imagined linguistic behaviour. ${ }^{9}$ If so, then the individual should be charitable and translate away the deviance of her counterpart's imagined utterances. But we have introduced some unnecessary machinery. The individual need not imagine a counterpart exhibiting linguistic behaviour; she need only countenance a new principle or the negation of one of the principles she antecedently accepts. That is, she can directly countenance a change to her accepted logical system; linguistic behaviour, real or imagined, need not enter the picture. For instance, she can think to herself 'What if $p$ and $\neg p$ ?' and consider the impact ' $p$ and $\neg p$ ' would have to her system of reasoning and to the inferences she makes. In doing so, she does not have to interpret a thing. She must simply be aware of the content of her own thoughts. And setting aside unconscious thoughts or conscious thoughts not currently accessed, she is. Since charity only enters the picture when we lack awareness of a person's thoughts, there is no need for charity here. So Quine's translation argument does not rule out individual revision.

Rather, it rules out collaborative revision. On this view, revision could never involve debate, dialogue, explanation, persuasion, and so on. Now, to the extent that the principle of charitable translation is normative, it does not rule out the very possibility of communicating rivalry, since two people might simply fail to adhere to the principle. Rather, Quine normatively rules out the communication of rivalry. He thinks we should follow his principle of translation, and if we follow it, then we cannot communicate rivalry. ${ }^{10}$ This view is not at odds with any of the claims discussed in $\S 1$, since Quine never claims explicitly that rational

\footnotetext{
${ }^{9} \mathrm{I}$ am grateful to an anonymous reviewer for pointing out this objection.

${ }^{10}$ Priest argues that we should take the principle of translation to be defeasible (2006a, 172). If Quine means it to be defeasible, he should a) say so, and b) give us some sense of the conditions under which it can be defeated.
} 
revision can or should be collaborative. ${ }^{11}$ So there is no full-on inconsistency in Quine with regard to the rational revisability of logic.

\section{$\S 2.2$ Change of Subject}

In Ch. 6 of Philosophy of Logic, Quine claims that deviant logicians and classical logicians cannot genuinely debate logic, because they respectively discuss different subject matters. According to Quine, when logicians attempt to formulate deviant principles, the deviance is "merely... notational and phonetic" $(1970,81)$. If a logician were to take the laws that classically govern disjunction to govern conjunction instead, and vice versa, Quine would say that the logician has "For obscure reasons, if any... taken to writing 'and' in place of 'or' and vice versa" $(1970,81)$. So when a person "espouses a logic whose laws are ostensibly contrary to our own, we are ready to speculate that he is just giving some familiar old vocables ('and', 'or', 'not', 'all', etc.) new meanings" (1960b, 59). Regarding the "popular extravaganza" rejecting the law of non-contradiction, Quine says that no participant in the debate

knows what he is talking about. They think they are talking about negation, ' $\sim$ ', 'not'; but surely the notation ceased to be recognizable as negation when they took to regarding some conjunctions of the form ' $p \cdot \sim p$ ' as true, and stopped regarding such sentences as implying all others. Here, evidently, is the deviant logician's predicament: when he tries to deny the doctrine he only changes the subject. $(1970,81)$

When the symbol that normally indicates classical negation is used differently, we are no longer talking about the same thing. The subject has changed from negation to something else. If so, then deviant logicians and classical logicians talk past one another. The classical logician speaks of one particular set of laws, while the deviant logician speaks of another.

The change of subject argument prima facie precludes the rational revisability of logic for the following reason. If the deviant logician and the classical logician talk past one another, then it is unclear how they could possibly articulate a disagreement. Disagreement occurs only with respect to some shared subject matter - for instance, the nature of conjunction as such. However, the two logicians share no subject matter, and in Quine's view, there is no 'nature of conjunction as such' (1970, 81). There is "no residual essence of conjunction and alternation in addition to the sounds and notations and the laws in conformity with which a man uses those sounds and notations" $(1970,81)$. That is, there is no fact of the matter about what a connective means over and above the meanings that we assign to it in practice. Since there is a plurality of practices, there is a plurality of meanings. There is no 'one true' subject matter about which to debate. Prima facie, if there is no genuine disagreement, there

\footnotetext{
${ }^{11} \mathrm{He}$ does claim that there is no difference in principle between logical revision and scientific revolution, and scientific revolutions are certainly collaborative. However, this piece of evidence is too weak to support a claim that Quine is flat-out inconsistent.
} 
is no genuine rivalry - the various systems do not compete against or conflict with one another. If there is no genuine rivalry, then there is no possibility of revision. ${ }^{12}$

That said, the change of subject argument is not really at odds with the rational revisability of logic. That is because Quine does not establish full incommensurability among logics. Even if there are different subject matters at issue, they can surely be adjudicated, either by making use of overlap between systems or by adopting a metalanguage that is neutral between them. What Quine's argument does show is that rival logics are not rivals in the sense of contradicting one another, but in the sense of being theoretical alternatives. Quine even admits that there may be good reasons for selecting a different theoretical alternative:

whoever denies the law of excluded middle changes the subject. This is not to say that he is wrong in so doing. In repudiating ' $p$ or $\sim p$ ' he is indeed giving up classical negation, or perhaps alternation, or both; and he may have his reasons. (Quine 1970, 83).

In other words, changing the subject can be rational. For instance, one might give up bivalence in the interests of accommodating vagueness (Quine 1981, 94). So the change of subject argument does not rule out the rational revisability of logic; it merely refines our understanding of rivalry.

In sum: although the principle of charitable translation and the change of subject argument prima facie rule out the rational revisability of logic, neither actually rules it out. ${ }^{13}$ The change of subject argument merely characterizes rational revision rather than refuting its possibility. The principle of charitable translation, however, normatively rules out collaborative revision. If we accept the normative constraint placed on us by the principle of charitable translation, we are left with the following thesis:

Quine's Revisability Thesis: Logic is rationally revisable, but only at the level of the individual.

The thesis holds that I can personally revise the logic that I accept or use, but I cannot communicate the revision to others, or coordinate with others to achieve collaborative revision. Quine's Revisability Thesis is weak, insofar as it severely limits the manner of revision. It also suggests, implausibly, that logicians who seem to discuss rival logics intelligibly either i.) don't, or ii.) fail to be charitable. However, I will argue that we can square a more robust revisability thesis with Quine's framework - one that preserves the possibility of genuine debate and collaborative revision. Here we depart from pure exegesis.

\footnotetext{
${ }^{12}$ Against Quine's change of subject argument, see the flourishing literature on logical pluralism: Allo (2007); Beall and Restall (2000), (2001) and (2006); Cook (2010); Dicher (2016); Goddu (2002); Lynch (2008); Restall (2002); Russell (2008); Wyatt (2004), and van Benthem (2008). See also Field (2009), Keefe (2014), and Priest (2001) in response.

${ }^{13}$ I have treated the translation argument and the change of subject argument separately. Compare Warren (2016), who sees the translation argument as an argument for a 'change of logic, change of meaning' thesis, and defends the thesis.
} 


\section{$\S 3$ Neo-Quinean Revisability}

So far I have argued that the apparent tension in Quine's work regarding the rational revisability of logic dissolves on analysis. His change of subject argument simply characterizes rival logics as theoretical alternatives - and one may have reasons for choosing a certain theoretical alternative over others. His principle of charitable translation, on the other hand, makes more trouble and rules out collaborative revision. So we are left with the Quinean Revisability Thesis, which permits only individual revisions. In the next section, I will show how Quine's framework can be augmented to support genuine debate and collaborative revision.

\section{$\S 3.1$ Distinctions}

To square the possibility of genuine debate and collaborative revision with Quine's framework, I distinguish between: 1) logic in theory and logic in practice, 2) laymen's logic and considered logic, and 3) evolutionary and revolutionary revision of logic.

\section{Distinction 1: logic in theory versus logic in practice}

This distinction is meant to track, roughly, the medieval distinction between logica docens and logica utens, which Peirce (1985) makes use of and to which Priest (2014) assigns importance. ${ }^{14}$ According to Peirce:

a man cannot truly reason without having some notions about the classification of arguments. But the classification of arguments is the chief business of the science of logic; so that every man who reasons... has necessarily a rudimentary science of logic, good or bad. The slang of the medieval universities called this his logica utens, - his 'logic in possession', - in contradistinction to logica docens, or the legitimate doctrine that is to be learned by study. $(1985,891-892)$

Logica utens refers to the manner in which individuals classify arguments in practice; logica docens refers to something more explicitly theoretical. The distinction is a useful one. By logic in theory, I mean abstract sets of logical principles and rules of inference. By logic in practice, I mean actual inferential practices.

\section{Distinction 2: laymen's logic versus considered logic}

Next, I distinguish laymen's logic from what I will call considered logic. Laymen's logic is the pre-theoretic set of inferential practices that, according to Quine, most people engage in. There are some abstract principles underlying those practices, which may or may not be consciously recognized. Those principles are the ones that, Quine thinks, would strike most people as obvious were

\footnotetext{
${ }^{14} \mathrm{I}$ wish to credit Graham Priest for drawing my attention to this distinction.
} 
they made explicit: the classical principles. ${ }^{15}$ Laymen's logic is what Quine frequently calls "our logic" (e.g. 1970, 81, 82, 83). Laymen's logic is the practiced logic of a very broadly construed community of individuals who need not explicitly recognize any theory of logic.

Considered logic, on the other hand, must be accompanied by some theoretical knowledge. A considered logic could be a theory that is consciously held or a practice that is informed by a background of theoretical knowledge. Considered logic need not be classical.

\section{Distinction 3: evolutionary versus revolutionary revision of logic}

The final distinction hinges primarily on the speed and scope of the revision. Revolutions occur quickly and all at once; evolution occurs gradually, in a piecemeal manner. Revolutionary revision may consist in the rejection of a single classical principle, such as the law of excluded middle in the case of intuitionistic logic, or the distribution principle in the case of quantum logic. It may also consist in the rejection of several principles. Evolutionary revision may also be of broad or of narrow scope. When the revision is narrow in scope - say, a matter of adopting or rejecting a single principle - it is prima facie unclear how the revision could proceed gradually. However, it can proceed gradually for a couple of reasons. First, though revision does not require consensus at the level of a community, one might wish to establish it, and doing so would require time. Moreover, recall that rational revision involves justifying the revision, which may also take time.

\section{§3.2: Distinctions Brought to Bear}

With the above distinctions in hand, we may now square the possibility of collaborative revision with Quine's framework. The Neo-Quinean resolution has two components:

1) The translation argument normatively rules out revolution with respect to laymen's practice (but not its evolution).

2) The arguments in favour of rational revision allow evolution and revolution with respect to considered logics, both theories and practices.

According to the first component, the translation argument rules out very rapid changes to the practice of the laymen. That is because the logic that we impose in translation is the logic of the laymen - according to Quine, it is their logic that is obvious, actually or potentially. What is obvious is not subject to revolution, because when it comes to obvious principles, "It is hard to face up to the rejection of anything so basic" $(1970,84)$. The obvious is entrenched, so it resists changing all at once. ${ }^{16}$ Moreover, since laymen's logic is shared, its revolution would require massive social coordination - it would require that the

\footnotetext{
${ }^{15}$ Just as it is not clear that most people find the classical principles obvious (see fn. 8), it is not clear that laymen's logic is in fact classical. Whether it is, is an empirical question. Any advocate of the Neo-Quinean view would have to support with evidence the claim that laymen's logic is classical.

${ }^{16}$ See Carlson (2015) for discussion of this aspect of Quine's view.
} 
masses suddenly change their inferential practices. Since the translation argument precludes such coordination from being achieved via linguistic persuasion, such coordination would be highly coincidental and so is fantastically unlikely. And what could motivate everyone, all at once, to change their practices? Because this massively coincidental, mysteriously motivated social coordination is virtually impossible, the Neo-Quinean rules out revolutionary revision.

However, the Neo-Quinean does not rule out evolutionary revision. Though the obvious is entrenched, it can still undergo gradual change. As Quine puts it: "logic is integral to our system of the world and accessible to change in the same way as the rest [of the system]. Obviousness resists change but does not preclude it" $(1990,36)$. That is, what people unhesitatingly assent to can change, but it must do so gradually. This evolutionary picture of the revision of laymen's logic fits well with Quine's comment that, regarding revision, he is "urging... a doctrine of gradualism" $(1970,100)$.

Without explicit theoretical reasons, what could motivate evolutionary revision of laymen's logic? Well, we might find that certain inferential practices just work better for whatever pragmatic purposes we have. From Quine's point of view, this isn't very likely (our logic resists change), but to the extent that we can't a priori rule out anything, we can't a priori rule out such an impetus for changing our practice. So, while it is difficult to imagine what could possibly motivate everyone to change their inferential practices all at once, it is less difficult to imagine that we might gradually discover that certain alternative inferential practices just serve us better.

Now, how could this gradual evolution of laymen's practice proceed? Since laymen's logic is pre-theoretic, the change would be a change to our inferential practices, not necessarily to any of our explicit beliefs. So a revision of laymen's logic wouldn't necessarily require communication, or interpretation, of deviant principles. We could just change, over time, the way we respond to the situations and stimuli we are presented with, as well as the responses we accept from others. That is, we could just change how we infer and which inferential outputs we accept. As Resnik puts it:

Just as we carry out this practice largely without thinking, we also revise it largely without thinking. We simply no longer accept specific inferential connections or, more frequently, we recognize new ones. Like changes in a language certain inferential practices may slowly and quietly become obsolete and new ones may unceremoniously evolve. $(2004,189)$

Inferential practices can evolve just as linguistic practices do. But the evolution of linguistic practices hinges on non-standard uses of language being understood. Likewise, doesn't the evolution of inferential practices hinge on nonstandard inferential outputs like ' $p$ and not $p$ ' being understood? And doesn't the translation argument rule that out? I answer no to both. First, we don't have to understand each other for our practices to change. We simply have to behave differently. Second, the translation argument only precludes someone whose practice accords with classical principles from understanding inferential 
outputs that do not accord with those principles. It doesn't preclude communication among individuals who have converged on some set of shared inferential practices through independently undertaken revisions. While such convergence might seem wildly implausible, we must remember that the revisions we undertake are driven by the same forces: the worldly phenomena we are presented with and the pragmatic purposes we often share. And to the extent that the revisions would occur piecemeal and the convergence emerge gradually, evolutionary revision wouldn't require, as revolutionary revision would, sudden, coincidental, massive social coordination. Rather, the evolution of laymen's practice would be initiated by brave individuals adapting to their worldly situation and in accordance with their pragmatic purposes. ${ }^{17}$ If the practices really do serve us better, then conceivably, a critical mass of these individual revisions may occur and a community of non-standard inferrers form. Those outside the community could observe its members' non-standard practices and imitate them. The practices could spread and the community expand. Ultimately, what started as the non-standard practices of a few eccentric individuals could become standard. If so, then an evolutionary revision of laymen's logic will have occurred. Again, Quine does not take any of this to be likely, since our practice of assent resists change. Nevertheless, the point is that it can change, but only through evolutionary revision.

Note that this evolutionary revision of laymen's logic is not yet the sort of collaborative revision I set out to square with Quine's framework. It cannot proceed via debate and dialogue. But we shouldn't expect it to, since laymen's logic is just a set of pre-theoretic practices and the changes to that practice occur 'largely without thinking'. Collaborative revision enters via the second component of the Neo-Quinean solution, which I turn to now.

The second component of the Neo-Quinean resolution holds that considered logics can be revised in whatever manner - through evolution or revolution. In fact, as I noted above, Quine explicitly likens revision to revolution on more than one occasion (1951, 43 and 1970,100). Considered logics are subject to both kinds of revision because, unlike laymen's logic, they are not entrenched they are not 'integral to our system of the world'. Switching between considered logics is usually not devastating to the shape of one's belief structure. So these considered principles are amenable to change in a way that laymen's practice isn't. Moreover, considered logical systems are usually adopted for theoretical or heuristic reasons. From a theoretical or heuristic point of view, it would not be silly to accept a contradiction. So charity does not require that we translate away the deviance of principles of considered logics. This means that although evolutionary revision of laymen's logic cannot proceed collaboratively, revisions of considered logics can. Neither revolution nor evolution with respect to considered logics is problematic from the Neo-Quinean point of view. So we are left with the following thesis:

\footnotetext{
${ }^{17}$ Brave to the extent that, as Resnik points out, "Consciously going against your perceptions of what your audience expects you to conclude requires a great deal of intellectual courage... [since] sanctions for making 'obvious errors' in logic are severe" (2004, 190).
} 
Neo-Quinean Revisability Thesis: All logics are rationally revisable in some manner or other; laymen's logic is rationally revisable only by evolution, while considered theories and practices are rationally revisable by evolution and by revolution.

Recall that the weak Quinean thesis we saw above claimed that logic, broadly understood, is revisable in just one way: by individuals, independently of others. By contrast, the Neo-Quinean thesis allows some revisions - revisions of considered logics - to involve and even hinge on successful acts of communication, and therefore allows them to be collaborative. While the Quinean Revisability Thesis is somewhat weak and unsatisfying, the Neo-Quinean Revisability Thesis enables a more robust, interesting, and nuanced picture of revision.

\section{$\S 4$ Conclusion}

There is an apparent tension in Quine's work regarding the rational revisability of logic. On the one hand, he avows its rational revisability, commits himself to universal revisability, and articulates criteria for choice among logics. On the other hand, the principle of charitable translation (or obviousness preservation) and the 'change of logic, change of subject' argument seem to rule out rational revisability. I argued that the 'change of subject' argument merely characterizes rivalry, rather than showing its in principle impossibility. The translation argument normatively rules out genuine debate and collaborative revision, but it allows revision by individuals. So Quine's commitment to the revisability of logic is consistent, but unsatisfying. However, I argued that by augmenting Quine's framework with the distinctions between 1) logic in theory and logic in practice, 2) laymen's logic and considered logic, and 3) revolutionary and evolutionary revision, the Neo-Quinean can commit to a more satisfying revisability thesis. According to the Neo-Quinean view that I articulate, everything is revisable in some manner or other, and the principle of charitable translation merely rules out the revolution of laymen's logic.

Australasian Journal of Logic (14:1) 2017, Article no. 2 


\section{Works Cited}

Allo, Patrick. 2007. "Logical Pluralism and Semantic Information." Journal of Philosophical Logic 36 (6): 659-694.

Arnold, Jack, and Stewart Shapiro. 2007. "Where in the (World Wide) Web of Belief Is the Law of Non-Contradiction?" Noûs 41 (2): 276-297.

Beall, J.C. 2009. Spandrels of Truth. Oxford: Oxford UP.

-, and Greg Restall. 2000. "Logical Pluralism." Australasian Journal of Philosophy 78 (8): 475-493.

—, and Greg Restall. 2001. "Defending Logical Pluralism." In Logical Consequence: Rival Approaches, Proceedings of the 1999 Conference of the Society of Exact Philosophy, 1-22. Stanmore: Hermes.

—, and Greg Restall. 2006. Logical Pluralism. Oxford: Oxford UP.

Berger, Alan. 2011. "Kripke on the Incoherency of Adopting a Logic." In Saul Kripke, edited by Alan Berger, 177-208. Cambridge, MA: Cambridge UP.

Booth, Richard, and Eva Richter. 2005. "On Revising Fuzzy Belief Bases." Studia Logica 80 (1): 29-61.

Burgess, John. 2012. Philosophical Logic. Princeton: Princeton UP.

Carlson, Matthew. 2015. "Logic and the Structure of the Web of Belief." Journal for the History of Analytical Philosophy 3 (5): 1-26.

Chase, James Kennedy. 2012. "The Logic of Quinean Revisability." Synthese 184: 357-373.

Cobreros, Pablo, Paul Egré, David Ripley, and Robert van Rooij. 2012. "Tolerant, Classical, Strict." Journal of Philosophical Logic 41 (2): 347-385.

Cook, Roy. 2010. "Let a Thousand Flowers Bloom: A Tour of Logical Pluralism." Philosophy Compass 5 (6): 492-504.

Dicher, Bogdan. 2016. "A Proof-Theoretic Defence of Meaning-Invariant Logical Pluralism." Mind 125 (499): 727-757.

Dummett, Michael. 1978a. "Is Logic Empirical?" In Truth and Other Enigmas, 269-289. Cambridge, MA: Harvard UP.

- 1978b. "The Philosophical Basis of Intuitionistic Logic." In Truth and Other Enigmas, 215-247. Cambridge, MA: Harvard UP.

Field, Hartry. 2003. "The Semantic Paradoxes and the Paradoxes of Vagueness." In Liars and Heaps: New Essays on Paradox, edited by J.C. Beall, 262-311. Oxford: Oxford UP. 
—. 2009. "Pluralism in Logic." Review of Symbolic Logic 2 (2): 342-359.

Goddu, G.C. 2002. "What Exactly Is Logical Pluralism?" Australasian Journal of Philosophy 80 (2): 218-230.

Haack, Susan. 1974a. " 'Alternative' in 'Alternative Logic.' " In Deviant Logic: Some Philosophical Issues, 1-21. Cambridge: Cambridge UP.

-. 1974b. "Reasons for Deviance." In Deviant Logic: Some Philosophical Issues, 25-42. Cambridge: Cambridge UP.

—. 1996. Deviant Logic, Fuzzy Logic: Beyond the Formalism. Chicago: University of Chicago Press.

Katz, Jerrold. 2000. Realistic Rationalism. Cambridge, MA: Bradford.

Keefe, Rosanna. 2014. "What Logical Pluralism Cannot Be." Synthese 191 (7): 1375-1390.

Lynch, Michael. 2008. "Alethic Pluralism, Logical Consequence and the Universality of Reason." Midwest Studies in Philosophy 32 (1): 122-140.

Mares, Edwin. 2002. "Relevance Logic." In A Companion to Philosohical Logic, edited by Dale Jacquette, 609-627. Malden, MA: Blackwell.

Peirce, Charles Sanders. 1985. "The Proper Treatment of Hypotheses: A Preliminary Chapter, Toward an Examination of Hume's Argument Against Miracles, in Its Logic and in Its History." In Historical Perspectives on Peirce's Logic of Science: A History of Science. Vol 2, edited by Carolyn Eisele, 890-904. Berlin: Mouton Publishers.

Priest, Graham. 2001. "Logic: One or Many?" In Logical Consequence: Rival Approaches, Proceedings of the 1999 Conference of the Society of Exact Philosophy, 23-28. Stanmore: Hermes.

—. 2006a. "Logic and Revisability." In Doubt Truth to Be a Liar, 155-175. Oxford: Oxford UP.

—. 2006b. "Rational Belief." In Doubt Truth to Be a Liar, 119-129. Oxford: Oxford UP.

-. 2008. An Introduction to Non-Classical Logic: From If to Is. 2nd Ed. Cambridge: Cambridge UP.

—. 2014. "Revising Logic." In The Metaphysics of Logic, edited by Penelope Rush, 211-223. Cambridge: Cambridge UP.

Putnam, Hilary. 1957. "Three-Valued Logic." Philosophical Studies 8 (5). Cambridge: Cambridge UP: 73-80.

Quine, Willard van Orman. 1951. "Two Dogmas of Empiricism." Philosophical Review. Cambridge, Mass: Harvard UP, 20-46. 
—. 1960a. "Carnap and Logical Truth." Synthese 12 (4): 350-374.

—. 1960b. Word and Object. Cambridge, MA: MIT Press.

—. 1970. Philosophy of Logic. Englewood Cliffs, NJ: Prentice-Hall.

—. 1981. "What Price Bivalence?" Journal of Philosophy 78 (2): 90-95.

—. 1983. "Vagueness and Alternative Logic." Erkenntnis 19 (1-3): 297-314.

—. 1990. "Comment on Berger." In Perspectives on Quine, edited by Robert Barrett and Roger Gibson, 36-37. Cambridge, MA: Blackwell.

Resnik, Michael. 2004. "Revising Logic." In The Law of Non-Contradiction, edited by Graham Priest, J.C. Beall, and Bradley Armour-Garb, 178-194. Oxford: Oxford UP.

Restall, Greg. 2002. "Carnap's Tolerance, Meaning, and Logical Pluralism." Journal of Philosophy 99 (8): 426-443.

Ripley, David. 2013a. "Paradoxes and Failures of Cut." Australasian Journal of Philosophy 91 (1): 139-164.

—. 2013b. "Revising Up: Strengthening Classical Logic in the Face of Paradox." Philosopher's Imprint 13 (5): 1-13.

Roeper, Peter. 2004. "A Sequent Formulation of Conditional Logic Based on Belief Change Operations." Studia Logica 77 (3): 425-438.

Russell, Gillian. 2008. "One True Logic?" Journal of Philosophical Logic 37 (6): 593-611.

Salerno, Joe. 2000. "Revising the Logic of Logical Revision." Philosophical Studies 99 (2): 211-227.

Shapiro, Stewart. 2000. "The Status of Logic." In New Essays on the A Priori, edited by Paul Boghossian and Christopher Peacocke, 333-338. Oxford: Oxford UP.

van Benthem, Johan. 2008. "Logical Pluralism Meets Logical Dynamics?" Australasian Journal of Philosophy 6: 182-209.

Warren, Jared. 2016. "Change of Logic, Change of Meaning." Philosophy and Phenomenological Research, 1-22.

Wright, Crispin. 1992. "Minimal Truth, Internal Realism and Superassertibility." In Truth and Objectivity, 33-70. Cambridge, MA: Harvard UP.

Wyatt, Nicole. 2004. "What Are Beall and Restall Pluralists About?" Australasian Journal of Philosophy 82 (3): 409-420. 